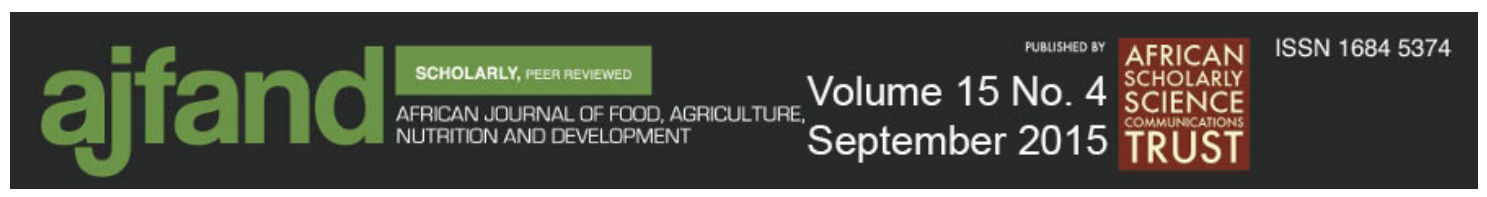

\title{
ASSOCIATION BETWEEN LIFESTYLE AND HEALTH VARIABLES \\ WITH NUTRITIONAL STATUS OF THE ELDERLY \\ IN THE NORTHERN REGION OF GHANA
}

Aganiba BA ${ }^{1^{*}}$ Owusu $\mathrm{WB}^{2}$, Steiner-Asiedu $\mathrm{M}^{3}$, Dittoh $\mathrm{S}^{4}$

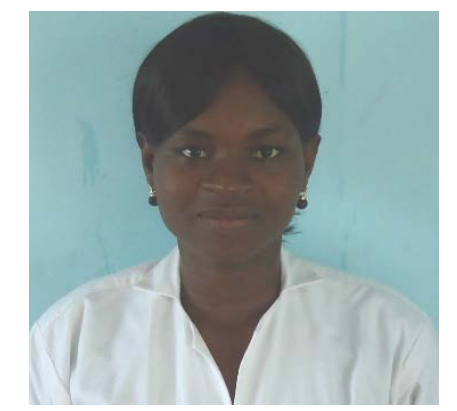

Benedicta Atulbire Aganiba

*Corresponding author email:atulbirebenedicta@yahoo.co.uk

${ }^{1}$ District Health Directorate, P. O. Box 82, Duayaw Nkwanta, Tano North -Brong Ahafo Region, Ghana, West Africa

${ }^{2}$ Department of Nutrition and Food Science, P. O. Box LG 134, University of Ghana, Legon, Ghana, West Africa (owusuwb@yahoo.com)

${ }^{3}$ Department of Nutrition and Food Science, P. O. Box LG 134, University of Ghana, Legon, Ghana, West Africa (tillysteiner@gmail.com)

${ }^{4}$ Food and Nutrition Security Unit, University for Development Studies, Tamale, Ghana, West Africa (saaditt@gmail.com) 


\begin{abstract}
With fertility and mortality steadily declining, a remarkable shift in the world's population age structure toward older ages is expected in the coming decades. The elderly population is at particular risk of malnutrition. The presence of malnutrition could be the result of, and also lead to, social, medical and other health problems. Currently, Ghana has the highest proportion of persons aged 60 years and above in sub-Saharan Africa and little attention has been given to this segment of the population. A cross-sectional study of 400 (177 males and 223 females) individuals who are 65 years and above was carried out in urban areas in the Northern Region of Ghana to evaluate the nutrition and health situation of the elderly. Socio-demographic and economic data, dietary patterns, state of health, level of physical activity and lifestyle variables were collected using a questionnaire. Anthropometric data (weight and height) were measured using standard procedures. More than half of the participants (56.2\%) were married and living with their spouses. These were mostly the males. Most of the participants (93.5\%) had no formal education while over half of them (57.2\%) relied on family members and friends for their financial needs. Slightly over half (53.2\%) of the subjects had fair health status with females experiencing more disease conditions than males. Almost all the respondents were independent in performing all daily activities. Using Body Mass Index (BMI) in $\mathrm{kg} / \mathrm{m}^{2}$ as an indicator for nutritional status, $18.0 \%$ of the participants were underweight, $60.5 \%$ had normal weight and $21.5 \%$ were overweight. Alcohol consumption and sight problems were found to have significant negative association with BMI ( $\mathrm{p}=0.007$ and $\mathrm{p}=0.005$, respectively). Malnutrition is, therefore, an important public health burden among the elderly in the region and therefore deserves attention. The formulation and implementation of a national policy on the elderly and nutrition education targeting the whole populace is urgently needed in Ghana to ensure healthy aging.
\end{abstract}

Key words: nutritional status, elderly, health, lifestyle, dietary intake, body mass index 


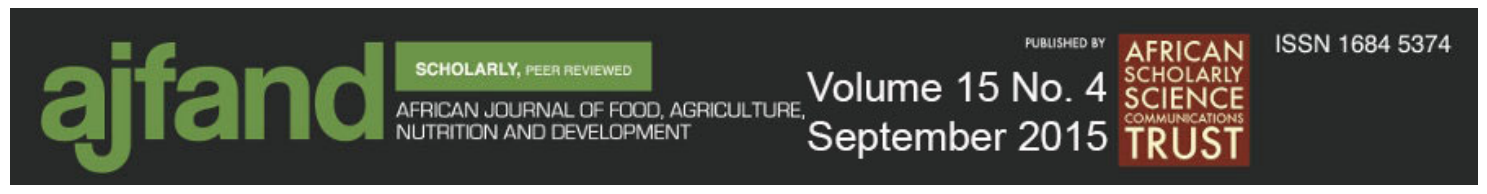

\section{INTRODUCTION}

According to the World Health Organization, nutritional status is an important component of physical and mental health for all age groups [1]. As the human body gets older, its nutritional needs and health concerns change due to an increasing susceptibility to degenerative diseases [2]. A prominent feature of aging is bone loss with concurrent low bone mineral density, a major predictor of fractures in the elderly population [3]. A normal part of aging is the loss of muscle mass and strength, which has been termed sarcopenia, from the Greek word "poverty of flesh". It is the fundamental cause of disability, functional dependence, falls, worsening outcome from other diseases among older persons [4]. The progressive accumulation of diverse and toxic changes with time increases the risk of morbidity and mortality among the elderly.

In Ghana, there has been a remarkable shift in population age structure toward the elderly. The 2000 Population and Housing Census Report showed that the proportion of the elderly (65 years and over) increased from $4.0 \%$ in 1984 to $5.3 \%$ of the population [5]. The aging of Ghana's population has been influenced by advances in public health services resulting in rapid decline in birth rate and mortality.

Aging is associated with significant changes in the physiological, physical, psychological and immune function, particularly cell-mediated immunity, resulting in progressive generalized impairment that increases susceptibility to infectious diseases [6]. The elderly are vulnerable to rapid degenerative processes, reduced efficiency of the gastrointestinal tract, loss of appetite due to a decline in sensory perception and a decline in health [7]. Also, eye problems, tooth loss/decay, rheumatism and hypertension are on the rise among the aged [8]. In spite of the vulnerability of the elderly, there is relatively little information on their nutritional status and general wellbeing in developing countries such as Ghana. In Northern Ghana, deprived areas are mostly found in the northern regions where a considerable proportion of the population can be categorized as elderly. It is this realization that prompted the design and execution of this study to examine the nutritional status and health profile of individuals who are 65 years and above in the Northern Region.

\section{MATERIALS AND METHODS}

\section{Study design and areas}

A cross-sectional study approach was used in the study to evaluate the nutrition and health situation of the elderly in the Northern region. Northern Region is one of the ten regions of Ghana with Tamale as the administrative capital. It has a total land area of $70,384 \mathrm{~km}^{2}$ with a total population of 1,820,806 of which the elderly constitute about $4.5 \%[5]$. 

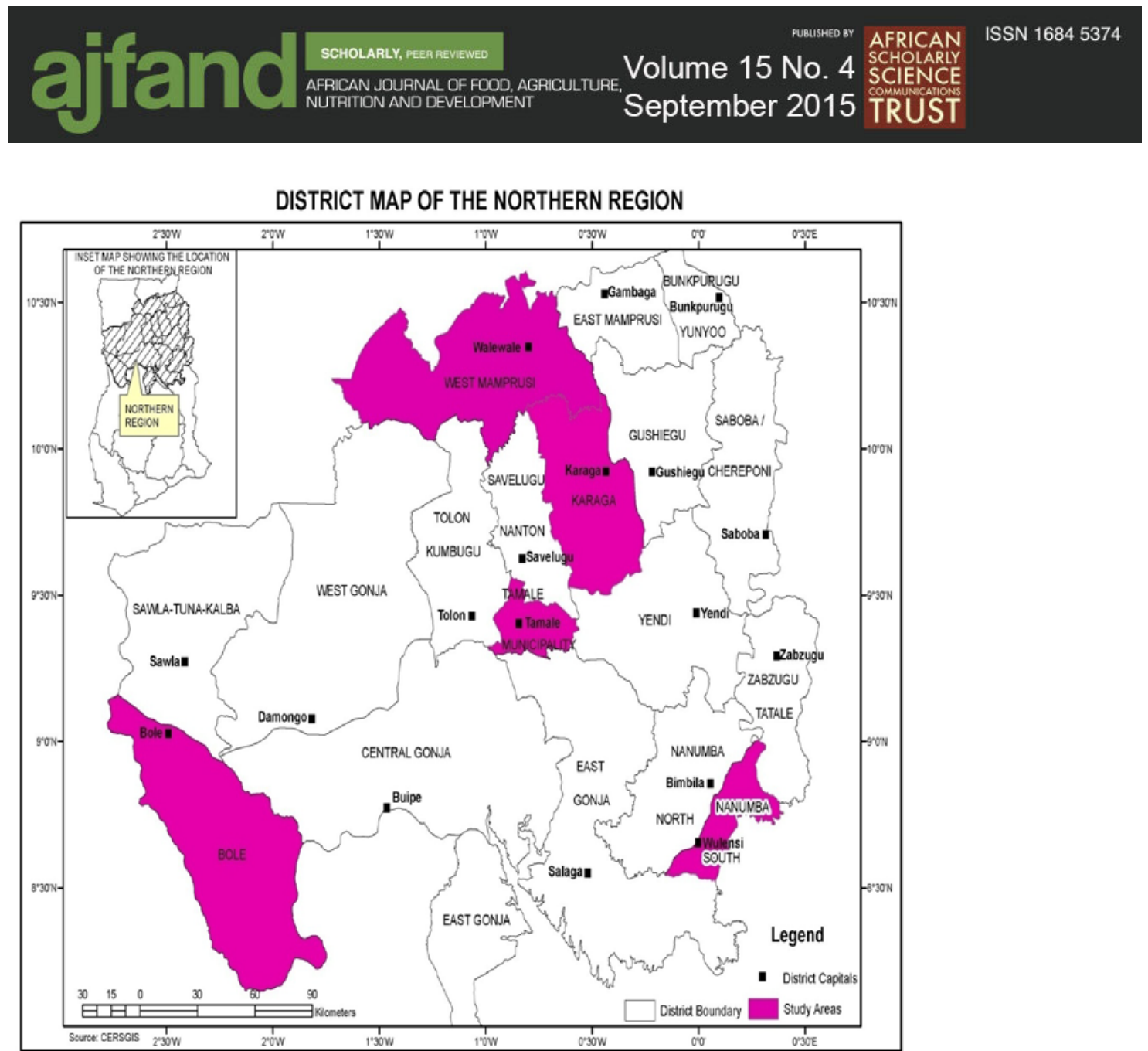

Figure 1: Map of Northern of Ghana Showing the Study Areas

\section{Study population, sample size and sampling technique}

The study population was the elderly in the northern region aged 65 years and above. Male and female individuals aged 65 years and above who lived in the selected district capitals were included. Those elderly who could not stand without aid were excluded from the study since helping them to stand on the weighing scale would affect their actual weight.

At a confidence level of 95\% with a confidence interval ( $\left.\mathrm{z}^{*}\right)$ of 1.96 and a 5\% (0.05) margin of error $(\mathrm{m})$, and a reasonable assumption that elderly persons of age 65 years and above constitute $5.3 \%$ of the Ghanaian population, a sample size (n) using the formula by Moore and McCabe below was used in this study [5, 9]. 


$$
\begin{aligned}
& \mathrm{n}=\left(\begin{array}{l}
\underline{\mathrm{z}^{*}} \\
2 \mathrm{~m}
\end{array}\right)^{2} \\
& \mathrm{n}=\left(\begin{array}{l}
\underline{1.96} \\
2(0.05)
\end{array}\right)^{2} \\
& \mathrm{n}=384.16 \\
& \mathrm{n} \approx 384
\end{aligned}
$$

A sample size of about 384 was required. However, this was rounded up to 400.

A three-stage sampling technique was used in the selection of the study participants. The region was stratified according to the five corridors (Northern, Eastern, Western, Southern and Central). One district was randomly selected from each corridor. Within each selected district, the capital was purposively chosen. In order to have a fair representation of the different ethnic groups and people from different backgrounds the district capitals were targeted. Various houses in the selected areas were visited. In each house visited, it was enquired if there were any individuals 65+ years of age. When eligible participants were found, they were informed either (alone or in the presence of other members of the household) about the purpose of the study and related issues indicated in the consent form. In houses where there were more than one elderly, only one of them was randomly selected by ballot. As many houses were visited until the required number of the elderly was obtained in each district.

\section{Data collection and analysis}

Interviews were conducted to collect data from individuals on socio-demographic and economic status, diet history and lifestyle. Weight and height measurements were taken using standard procedures [10]. Subjects were in minimum clothing (that is all extra clothing and other accessories like shoes, wrist watches, headgears, metallic bracelets, mobile phones, etcetera were removed) in order to get the actual weight of individuals. Weight measurements were done using a Seca-880 digital floor weighing scale with the participants standing upright and unsupported. Their weights were then recorded in duplicates to the nearest $0.1 \mathrm{~kg}$. Height was measured with the stadiometer set up against a vertical wall. Each of them stood upright with their heels, buttocks, shoulders and the back of their head against the stadiometer. With each participant looking straight ahead 


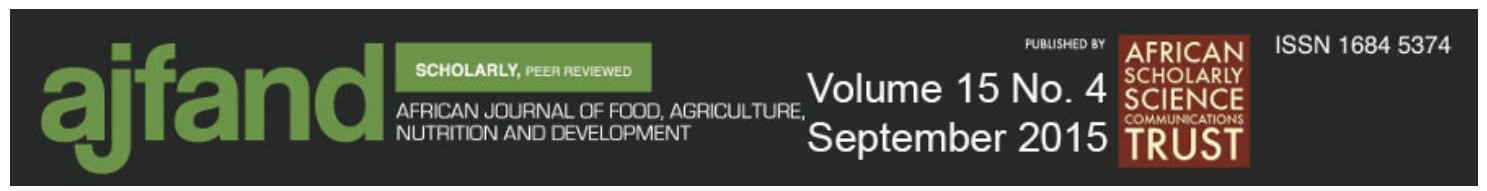

along the Frankfort plane, the headpiece was lowered to touch the crown of their head gently but firmly and the readings recorded in duplicates to the nearest $0.1 \mathrm{~cm}$. Body mass index (BMI) was computed as weight in $\mathrm{kg} /$ height in $\mathrm{m}^{2}$ for each subject and then classified as being underweight, normal, overweight or obese according to WHO cut-off ranges [10]. A data entry structure was developed in Microsoft Excel 2007 and Statistical Package for Social Sciences (SPSS, version 16). Basic descriptive statistics (frequencies, means, standard deviations and ranges) were run. Student's t-tests were performed to test for sex differences in mean anthropometric characteristics. The relationships between selected variables of interest were explored using standard multi-variable linear regression models in relation to the study objectives. Ethical approval was obtained from the Institutional Review Board (IRB) at the Noguchi Memorial Institute for Medical Research. Written informed consent was also sought from all participants for data collection, analysis and dissemination.

\section{RESULTS}

\section{Socio-demographic and economic background of participants}

The sample population of 400 was from five districts in the Northern Region of Ghana. These include Tamale Metropolitan $(n=156)$, West Mamprusi $(n=81)$, Bole $(n=76)$, Karaga $(n=44)$ and Nanumba South $(n=43)$. The study population comprised of 177 (44.2\%) males and 233 (55.8\%) females between the ages of $65-101$ years (Table 1 ).

More than half of the participants (56.2\%) were married while $43.0 \%$ had lost their spouses. There were more widows than widowers. The Dagomba ethnic group represents 49.3\% of the study population and is represented in all except the Nanumba South district. The Mamprusi are the next largest group, constituting 17.5\% of the participants, followed by the Gonja ethnic group (15.2\%). The Nanumba group formed $10.2 \%$ with the other ethnic groups with less than $10.0 \%$ representation thinly scattered among the districts. These proportions reflect the generally observed distribution of ethnic groups in the region.

Most of the participants (93.5\%) had no formal education and were mostly traders (51.2\%) and farmers (37.5\%) before their retirement age, and largely unemployed $(53.5 \%)$ in their old age. On the whole, the highest educational level attained by majority of the educated was middle/ JSS level. Over half of the participants (57.2\%) received income support from family members and friends.

\section{Anthropometric status of the elderly}

Table 2 outlines the background anthropometric characteristics of participants by sex. The mean weight of the study population $(58.4 \pm 13.6 \mathrm{~kg})$ was significantly higher among males than females $(\mathrm{p}<0.0001)$. The mean height of the participants which was $1.6 \pm 0.1$ $\mathrm{m}$ was also significantly higher in males than females $(\mathrm{p}<0.0001)$. The mean Body Mass Index (BMI) of the sample population was $22.4 \pm 4.6 \mathrm{~kg} / \mathrm{m}^{2}$ with men having a mean of $22.1 \pm 4.3 \mathrm{~kg} / \mathrm{m}^{2}$ and women a similar figure $22.6 \pm 4.9 \mathrm{~kg} / \mathrm{m}^{2}(\mathrm{p}=0.266)$.

The prevalence of the different classes of BMI calculated using height (BMI) is shown in Figure 2 below. About $18.0 \%$ of the participants had a BMI below $18.50 \mathrm{~kg} / \mathrm{m}^{2}$. More 


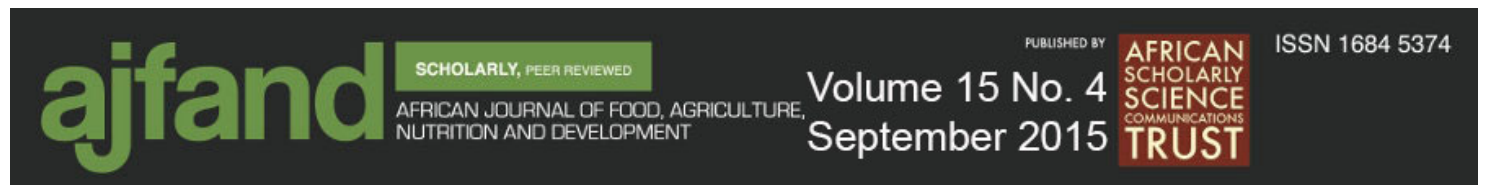

males (19.8\%) than females (16.6\%) had a BMI less than $18.50 \mathrm{~kg} / \mathrm{m}^{2}$. Majority $(60.5 \%)$ of the participants had a nutritional status considered to be normal with $63.3 \%$ males and $58.3 \%$ females being classified as normal. About $17.0 \%$ males and $25 \%$ females were overweight.

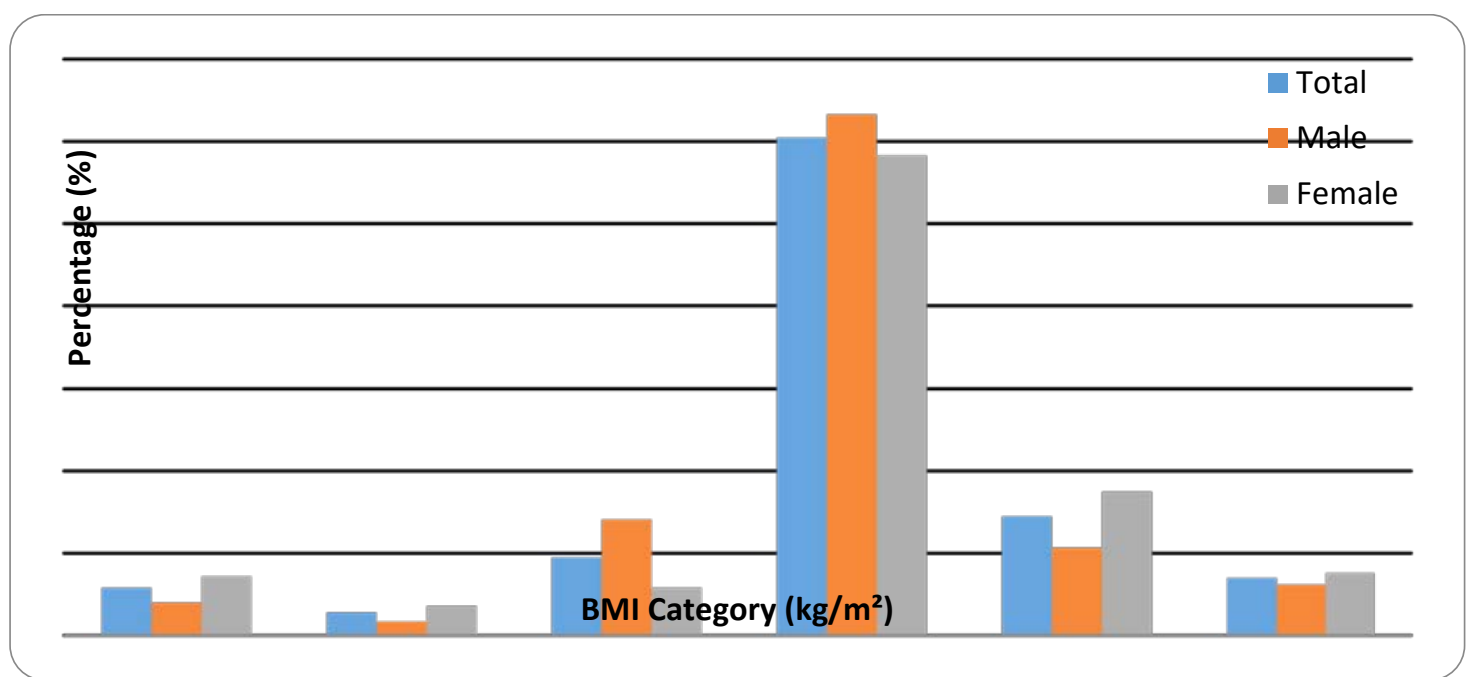

Figure 2: Distribution of BMI of Participants According to the WHO Classification [10]

\section{Lifestyle patterns, dietary intake and health status}

Table 3 summarizes the lifestyle and social activities observed among the participants. More than $80 \%$ of the participants (both males and females) did not habitually smoke, consume alcohol nor use other forms of tobacco (such as snuff). More than half of the participants (70.2\%) had social contacts for more than 3 times a week. These included visits by friends and family members and attendance of public gatherings such as mosque and church gatherings.

Food groups that were mostly consumed daily in the past week were fish and meat (95.8\%) and cereals and grains (95.2\%) (Figure 3). This was followed by fats and oils (80.5\%), legumes and nuts (69.8\%) and roots and tubers (57.0\%), which are consumed not less than 3 times a week. Daily consumption of fruits and vegetables was very minimal (5.0\%). None of the participants used nutrient supplements in the past 7 days. 


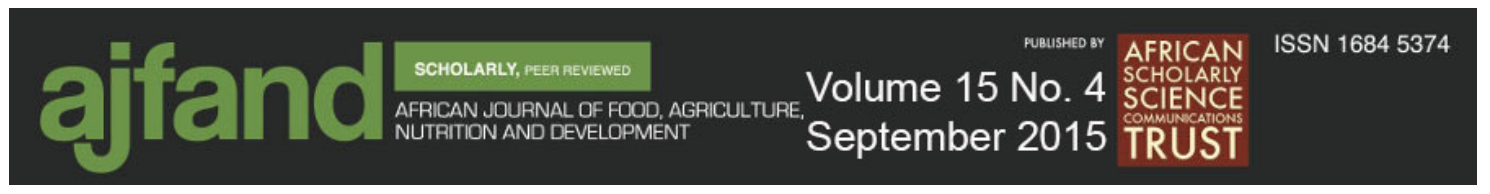

\section{Food Frequency in the past week (7 days)}

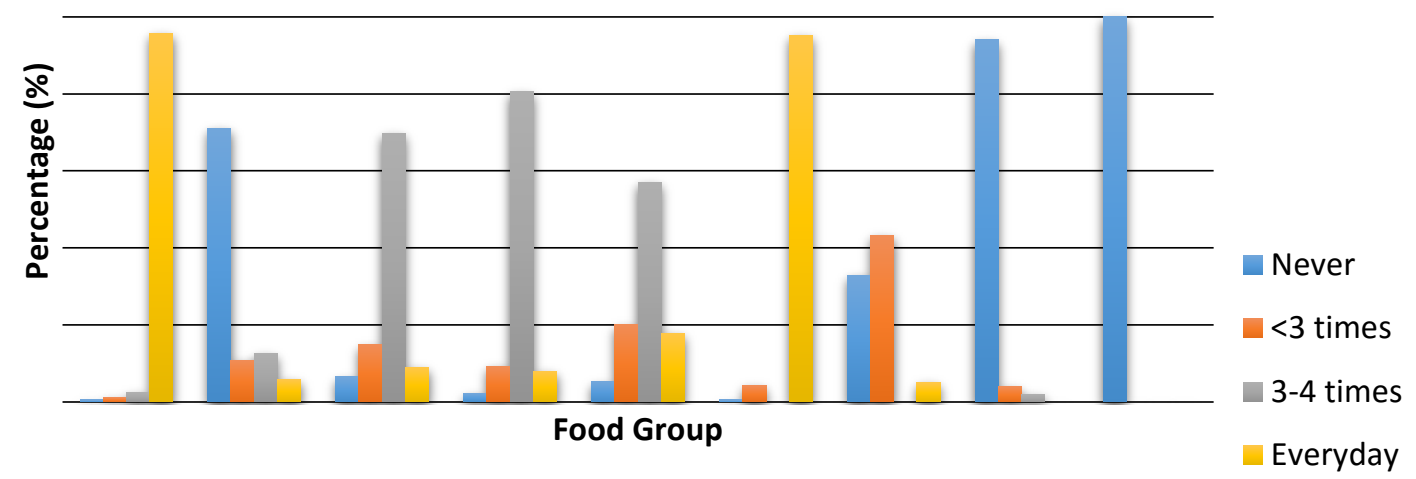

Figure 3:Food Intake and Nutrient Supplement Use among the Study Participants

Several questions were asked to assess the health status of the participants (Table 4). In order to evaluate the general health status, participants were asked to grade their overall health situation on a scale of excellent, good, fair and bad. A little over half (53.2 \%) of the participants reported having a "fair" health (neither poor nor good), while $46.8 \%$ reported being in "good" health. The majority of the participants (79.8\%) reported not being diagnosed with any disease. Among those with diagnosed conditions, cardiovascular disease, specifically hypertension was the most prevalent (8.5\%) followed by arthritis (2.7\%), digestive system diseases (2.7\%) and diabetes mellitus (2.3\%). More females than males were diagnosed with these conditions. The majority of the participants (94.2\%) reported having symptoms of disease in the previous week, $53.2 \%$ of whom had more than one symptom. This was more prevalent among females. A few (6.8\%) of the participants reported having hearing difficulty, with more females $(7.6 \%)$ reporting this difficulty. Approximately $35.4 \%$ of the female participants had sight problems, compared with $36.7 \%$ in their male counterparts. Close to a third (39.0\% for females and $26.6 \%$ males) had dental problems. About $70 \%$ of the participants (both males and females) had health insurance.

Table 5 shows independent contributions of factors associated with BMI. Alcohol consumption and sight problems were negatively and independently associated with BMI ( $\mathrm{p}=0.007$ and $\mathrm{p}=0.005$ respectively). Although, cigarette smoking made a negative contribution to BMI it was not significant. 


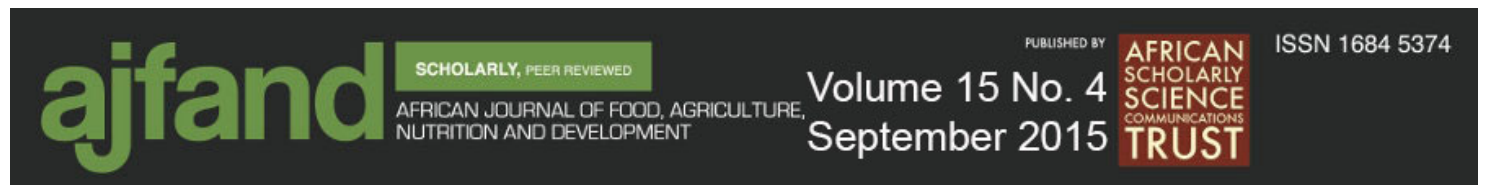

\section{DISCUSSION}

\section{Socio-demographic and economic information}

The study was a cross-sectional study that determined the nutritional status and health profile of 177 elderly males and 223 elderly females from five district capitals in the Northern Region of Ghana. The male to female ratio was consistent with the sex composition of the regional and national population [5]. There is relatively higher mortality among males along the life-span resulting in the higher proportions of females at older ages [11]. The percentage of males in the age group from 75 and older was however, higher (59.9\%) than that of females (42.24\%). This pattern of increasing proportion of males, at older age groups, may be attributed to the patriarchal nature of a population in which older males tend to exaggerate their age rather than to a higher survival of males at older ages [5].

Women are said to become widows early and remain single through life without the support and companionship of their spouse [12]. Whereas most women experience the death of their husbands and end their lives as widows, most men remain married until they die [13]. Widowhood has also been associated with increased mortality, morbidity and disability in both elderly males and females [14]. In this study, almost all of the few who reported having some form of physical disability or disease were widowed.

Earlier studies among elderly men and women have reported consistently that those widowed or unmarried and living alone are more likely to have impairment in food choices and intake that affect their nutritional status $[15,16]$. The results from this study show that of the over half (56.2\%) participants married, most were mainly having normal nutritional status. In relation to this, a greater proportion of the married participants had normal BMI. The majority of the participants had no formal education and was unemployed. They, therefore, relied on friends and other family members for their financial needs.

\section{Anthropometric status of the elderly}

The mean values of BMI of the participants of this study were below the lowest mean BMIs found in studies in 12 European countries (24.4 to $30.3 \mathrm{~kg} / \mathrm{m}^{2}$ for males and 23.9 to $30.5 \mathrm{~kg} / \mathrm{m}^{2}$ for females) [17]. This supports the finding that suggests that low body weight and small stature seem to be more prevalent in developing countries than developed countries [18]. A large proportion of the participants (60.5\%) had normal weight which is higher than the rate observed in a study in Accra where 49.2\% were identified as within the normal weight [19].

The rates of underweight among males and females in the current study are lower compared to studies carried out in Accra, Malawi and India, which ranged from $35.0 \%$ $62.0 \%$ for males and $27.0 \%-41.0 \%$ for females [19, 20, 21]. It is surprising the undernutrition rate was higher in Accra than this study area which is deprived and less developed. Furthermore, $7.2 \%$ of the women and $4.0 \%$ of the men who were underweight had grade III CED (Chronic Energy Deficiency) or severe underweight which is a reverse of what was observed in Accra and Nairobi (more males [30.0 and 32.3\%, respectively] than females [17.0 and 12.8\%, respectively] were severely underweight) [19, 22]. A 
study in Ethiopia, however, observed a higher proportion (30.0\%) but a similar trend of underweight among females (32.0\%) and males (19.0\%) [23]. The observed prevalence of underweight among female participants though relatively low, suggests they are acutely nutritionally vulnerable. Underweight and overweight classified by BMI has been shown to be risk factors for poor quality of life, morbidity and mortality [24, 25]. In the present study, $21.5 \%$ of the participants were overweight.

\section{Lifestyle patterns, dietary intake and health status}

The effects of tobacco and alcohol use on nutritional status have been extensively studied with moderate alcohol intake and non-smoking being found to be beneficial for healthy aging and protective against stroke [26, 27, 28]. Majority of the participants did not consume alcohol neither did they use tobacco or smoke cigarette. The relatively low proportions of participants who consumed alcohol was probably due to the unacceptability of this lifestyle practice in this Islamic dominant society.

A large proportion of the participants attended mosque and church activities, and were also visited by friends and other family members. Active engagement in social activities can improve the quality of life among the elderly. Also, older persons tend to thrive in situations where love, understanding and mutual respect exist [29]. This is probably a contributory factor to the normal nutritional status among the participants.

Chronic and acute diseases have been associated with poor nutritional status in the elderly [30, 31]. Diseases common among the participants were cardiovascular disease (specifically hypertension), arthritis and diabetes mellitus. This is consistent with the most frequently reported disorders among the elderly [32]. The relatively low proportions of participants reporting these diseases could probably be due to their engagement in simple physical activities such as walking. Good nutrition and simple physical activities have been found to improve non-communicable chronic diseases [33, 34]. Even though most of the participants were covered by the National Health Insurance Scheme, they did not seek frequent medical attention. This could have also contributed to most of them not reporting any diagnosed disease conditions.

\section{Relationship between lifestyle variables and BMI}

Excessive alcohol consumption has also been found to have negative effect on nutritional status of individuals [35]. The inverse relationship between alcohol consumption and BMI in this study implied that participants who drank alcohol were more likely to be underweight than those who did not. The high energy content of alcoholic beverage may cause primary malnutrition by displacing other nutrients when alcohol is consumed in large amounts [35, 36]. Also excessive alcohol consumption may interfere with the nutritional process and cause secondary malnutrition through mal-digestion and malabsorption caused by gastrointestinal problems related with high alcohol intake [35, 36].

Vision impairment normally measured as visual acuity (an indication of the clearness or clarity of one's vision), as well as cataract and age-related macular degeneration have been linked to dietary intake, cognitive decline and poor mobility [31, 37, 38]. A substantial proportion of the participants (36.0\%) had sight problems which could be contributing to the relatively high prevalence of malnutrition. Sedentary lifestyle 
practices among those having sight problems could result in overweight. Their inability to purchase and prepare food due to poor mobility on the other hand, could contribute to underweight.

In this study, tobacco use (cigarette smoking and not chewing of tobacco) had a negative effect on BMI. This association was however not significant. The use of tobacco and its association with low body mass index has been attributed mainly to the fact that smoking increases energy expenditure as well as the acute anorectic actions of nicotine [27, 39]. The inverse relationship between tobacco use and body mass index becomes stronger as an individual ages [40].

\section{LIMITATION}

Dietary intake relied on the ability of the participants to recall, which might have resulted in alteration and errors in their diet.

\section{CONCLUSION}

The study findings indicate that relatively high levels of malnutrition (under- and overnutrition) exist in the five districts. This can be extrapolated to other districts in the region. Malnutrition is therefore an important public health burden among the elderly in the study areas. Factors such as visual acuity and drinking of alcohol were found to be significant predictors of low BMI ( $\mathrm{p}=0.005$ and $\mathrm{p}=0.007$ respectively) in this study. There is evidence that the elderly people in spite of their vulnerability are not given enough attention as they should. It is also apparent that a lot more can be done to enhance the nutritional status and general wellbeing of the elderly in Ghana. It is therefore important to formulate and implement a national policy on the nutrition and health of the elderly targeting the whole populace to ensure healthy aging.

\section{ACKNOWLEDGEMENT}

The authors are grateful to the Northern Regional and the five District Health Directorates for consenting to work with us, as well as the interpreters who helped in the data collection. We also thank the elderly and their households for their willingness to participate in the study. Benedicta Atulbire Aganiba is grateful to her family members for their financial support, motivation, inspiration and encouragement. 


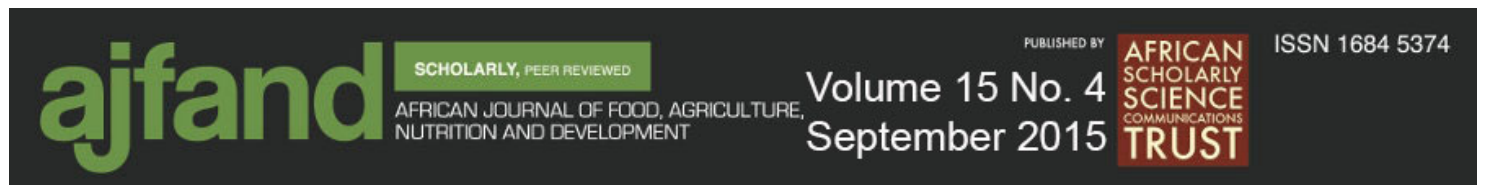

Table 1: Socio-Demographic and Economic Characteristics of Participants

\begin{tabular}{|c|c|c|c|}
\hline \multirow[t]{2}{*}{ Variables } & \multirow{2}{*}{$\begin{array}{c}\text { Total }(\mathrm{N}=400) \\
\mathrm{n}(\%)\end{array}$} & \multirow{2}{*}{$\begin{array}{c}\text { Male (n = } \\
177) \\
\mathbf{n}(\%) \\
\end{array}$} & \multirow{2}{*}{$\begin{array}{c}\text { Female }(\mathbf{n}= \\
223) \\
\mathbf{n}(\%)\end{array}$} \\
\hline & & & \\
\hline \multicolumn{4}{|l|}{ Age Category ${ }^{\mathrm{a}}$} \\
\hline $65-74$ & $200(50.0)$ & $71(40.1)$ & $129(57.8)$ \\
\hline $75-84$ & $146(36.5)$ & $80(45.2)$ & $66(29.6)$ \\
\hline 85 and above & $54(13.5)$ & $26(14.7)$ & $28(12.6)$ \\
\hline \multicolumn{4}{|l|}{ Marital Status } \\
\hline Married & $225(56.2)$ & $155(87.6)$ & $70(31.4)$ \\
\hline Divorced/Separated & $3(0.8)$ & $3(1.7)$ & $0(0.0)$ \\
\hline Widowed & $172(43.0)$ & $19(10.7)$ & $153(68.6)$ \\
\hline \multicolumn{4}{|l|}{ Ethnic Group } \\
\hline Dagomba & 197 (49.3) & $90(50.8)$ & $107(48.0)$ \\
\hline Mamprusi & $70(17.5)$ & $32(18.1)$ & $38(17.0)$ \\
\hline Gonja & $61(15.2)$ & $22(12.4)$ & 39 (17.5) \\
\hline Nanumba & $41(10.2)$ & $23(13.0)$ & $18(8.1)$ \\
\hline Konkomba & $2(0.5)$ & $2(1.1)$ & $0(0.0)$ \\
\hline Akan & $2(0.5)$ & $2(1.1)$ & $0(0.0)$ \\
\hline Others ${ }^{\mathrm{b}}$ & $27(6.8)$ & $6(3.4)$ & $21(9.4)$ \\
\hline \multicolumn{4}{|c|}{ Educational Background } \\
\hline None & $374(93.5)$ & $158(89.3)$ & 216 (96.9) \\
\hline Primary & $8(2.0)$ & $6(3.4)$ & $2(0.9)$ \\
\hline Middle/JSS & $13(3.3)$ & $9(5.1)$ & $4(1.8)$ \\
\hline Secondary/Technical & $0(0.0)$ & $0(0.0)$ & $0(0.0)$ \\
\hline Tertiary & $5(1.2)$ & $4(2.3)$ & $1(0.4)$ \\
\hline \multicolumn{4}{|c|}{ Pre-retirement Occupation } \\
\hline Unemployed & $2(0.5)$ & $0(0.0)$ & $2(0.9)$ \\
\hline Employed $^{\mathrm{c}}$ & 398 (99.5) & $177(100)$ & $221(99.1)$ \\
\hline \multicolumn{4}{|c|}{ Post-retirement Occupation } \\
\hline Unemployed & $214(53.5)$ & $79(44.6)$ & $135(60.5)$ \\
\hline Employed $^{\mathrm{C}}$ & $186(46.5)$ & $98(55.4)$ & 88 (39.5) \\
\hline \multicolumn{4}{|l|}{ Sources of Income } \\
\hline Salary & $9(2.3)$ & $8(4.5)$ & $1(0.4)$ \\
\hline Remittance $^{\mathrm{d}}$ & $229(57.2)$ & $82(46.3)$ & $147(65.9)$ \\
\hline Private Business & $80(20.0)$ & $45(25.4)$ & $35(15.7)$ \\
\hline Pension & $9(2.3)$ & $8(4.5)$ & $1(0.4)$ \\
\hline Two or more sources & $73(18.2)$ & $34(19.2)$ & $39(17.5)$ \\
\hline
\end{tabular}

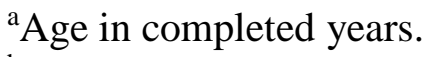

${ }^{\mathrm{b}}$ Others include Moshie, Grushie, Hausa, Dagarti, Waala

${ }^{c}$ Employed includes trader, farmer, teacher, security worker, office clerk, revenue officer, labourer, sanitary worker, pastors, drivers and artisans

${ }^{\mathrm{d}}$ Remittance include income support from family members and friends 


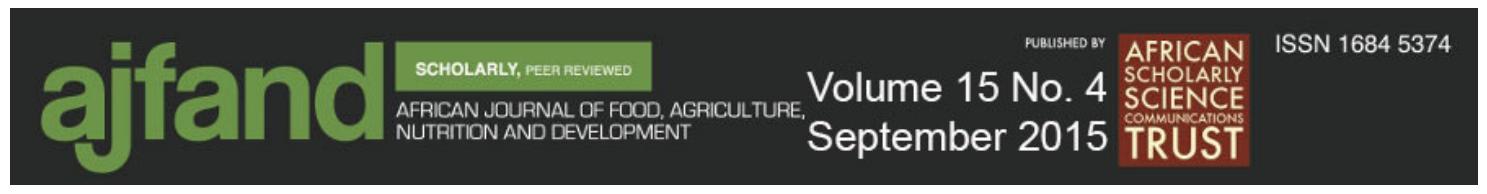

Table 2: Background Anthropometric Characteristics of Participants

\begin{tabular}{lcccc}
\hline Variables & All Districts & & \multirow{2}{*}{ p-value } \\
\cline { 2 - 4 } & Total (N = 400) & Male (n=177) & Female (n=223) & \\
\cline { 2 - 4 } & Mean (SD) & Mean (SD) & Mean (SD) & \\
\hline Age (y) & $75.0(7.8)$ & $76.7(7.9)$ & $73.7(7.4)$ & $<0.0001$ \\
Weight (kg) & $58.4(13.6)$ & $61.90(13.6)$ & $55.7(13.0)$ & $<0.0001$ \\
Height (m) & $1.6(0.1)$ & $1.7(0.1)$ & $1.6(0.1)$ & $<0.0001$ \\
BMI $^{\mathrm{a}}\left(\mathrm{kg} / \mathrm{m}^{2}\right)$ & $22.4(4.6)$ & $22.1(4.3)$ & $22.6(4.9)$ & 0.266 \\
\hline ANOVA is significant at the 0.05 level; ${ }^{\text {a }}$ BMI - Body Mass Index (weight in kg/height in $\left.\mathrm{m}^{2}\right)$
\end{tabular}

Table 3: Lifestyle and Social Activity Patterns of the Study Participants

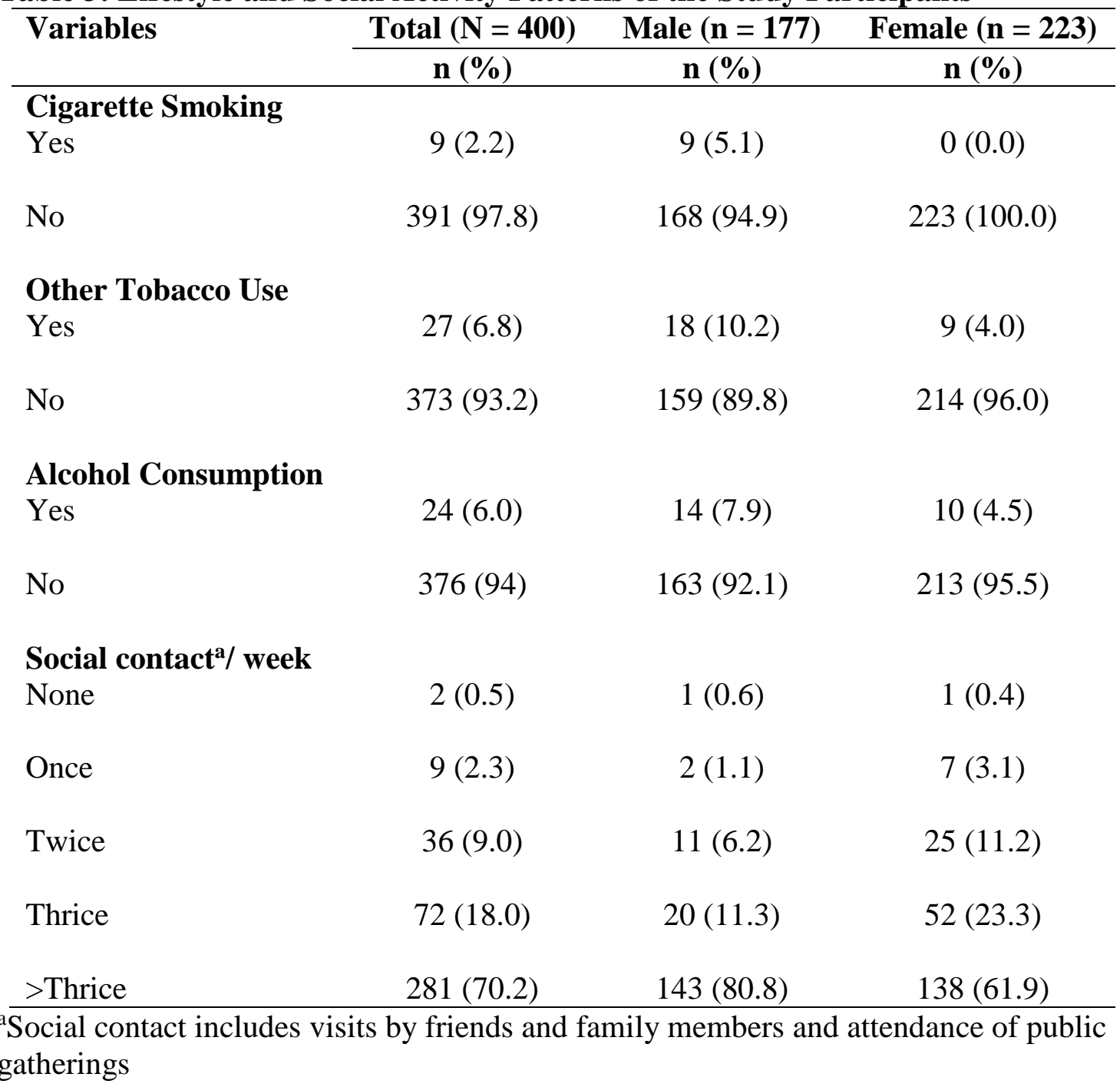




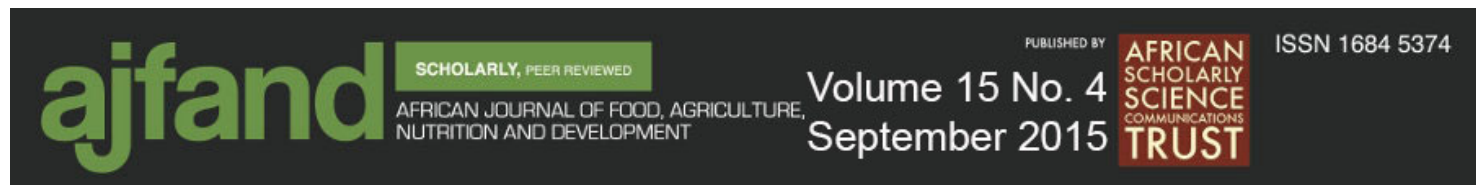

Table 4: Health Indicators of the Study Participants

\begin{tabular}{|c|c|c|c|}
\hline \multirow[t]{2}{*}{ Variables } & \multicolumn{3}{|c|}{ Frequency (\%) } \\
\hline & $\begin{array}{c}\text { Total } \\
(\mathrm{N}=\mathbf{4 0 0})\end{array}$ & $\begin{array}{c}\text { Male } \\
(\mathrm{n}=177)\end{array}$ & $\begin{array}{l}\text { Female } \\
(n=223)\end{array}$ \\
\hline \multicolumn{4}{|c|}{ Personal Opinion about Health } \\
\hline “Good” & $187(46.8)$ & $84(47.5)$ & $103(46.2)$ \\
\hline “Fair" & $213(53.2)$ & $93(52.5)$ & $120(53.8)$ \\
\hline \multicolumn{4}{|l|}{ Diagnosed Diseases $^{\mathrm{a}}$} \\
\hline Cardiovascular Diseases & $34(8.5)$ & $13(7.3)$ & $21(9.4)$ \\
\hline Arthritis & $11(2.7)$ & $4(2.3)$ & $7(3.1)$ \\
\hline Digestive System Diseases & $11(2.7)$ & $2(1.1)$ & $9(4.0)$ \\
\hline Diabetes Mellitus (DM) & $9(2.3)$ & $1(0.6)$ & $8(3.6)$ \\
\hline More than two & $6(2.0)$ & $5(2.8)$ & $1(0.5)$ \\
\hline Others $^{\mathrm{b}}$ & $10(2.5)$ & $6(3.4)$ & $4(1.8)$ \\
\hline None & $319(79.8)$ & $146(82.5)$ & $173(77.6)$ \\
\hline \multicolumn{4}{|c|}{ Symptoms of Disease in Past Week } \\
\hline One symptom ${ }^{\mathrm{c}}$ & $164(41)$ & $87(49.1)$ & $77(34.5)$ \\
\hline Two or more symptoms & $213(53.2)$ & $78(44.1)$ & $135(60.5)$ \\
\hline None & $23(5.8)$ & $12(6.8)$ & $11(5.0)$ \\
\hline \multicolumn{4}{|l|}{ Hearing Difficulty } \\
\hline Yes & $27(6.8)$ & $10(5.6)$ & $17(7.6)$ \\
\hline No & $373(93.2)$ & $167(94.4)$ & $206(92.4)$ \\
\hline \multicolumn{4}{|l|}{ Sight Difficulty } \\
\hline Yes & $144(36.0)$ & $65(36.7)$ & $79(35.4)$ \\
\hline No & $256(64.0)$ & $112(63.3)$ & $144(64.6)$ \\
\hline \multicolumn{4}{|l|}{ Chewing Difficulty } \\
\hline Yes & $134(33.5)$ & $47(26.6)$ & $87(39.0)$ \\
\hline No & $266(66.5)$ & $130(73.4)$ & $136(61.0)$ \\
\hline \multicolumn{4}{|l|}{ Health Insurance } \\
\hline Yes & $281(70.2)$ & $124(70.1)$ & $157(70.4)$ \\
\hline No & $119(29.8)$ & $53(29.9)$ & $66(29.6)$ \\
\hline
\end{tabular}

${ }^{a}$ The diseases had been diagnosed and confirmed by health care professionals. In most cases, they were on medications, 'bthers include cancer and Genitourinary Diseases, ${ }^{\mathrm{c}}$ One symptom include Headache Vertigo/ Dizziness Diarrhoea Constipation Stomach Pains Problems in Urinating Body Pains 


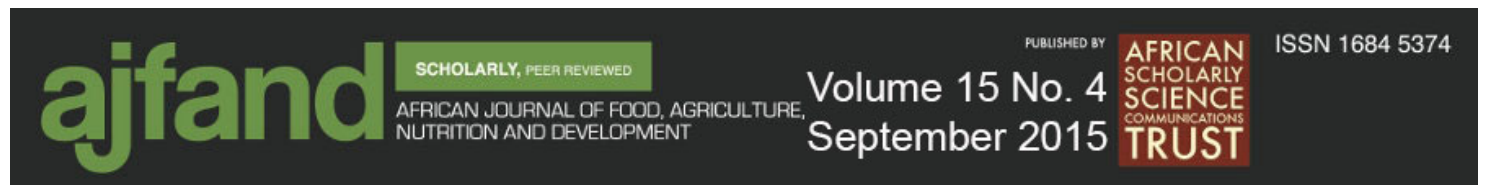

Table 5: Association between selected lifestyle and health variables with BMI $\left(\mathrm{kg} / \mathrm{m}^{2}\right)$ calculated using height

\begin{tabular}{lccc}
\hline Variables & \multicolumn{3}{c}{ BMI $^{\mathbf{a}} \mathbf{( k g / \mathbf { m } ^ { 2 } )}$} \\
\cline { 2 - 4 } Cigarette smoking & Beta & SE & p-value \\
Tobacco use (chewing) & 0.035 & 1.569 & 0.492 \\
Alcohol intake & -0.148 & 1.026 & 0.109 \\
Sight problems & -0.146 & 1.052 & $0.007^{*}$ \\
Dental problems & 0.004 & 0.502 & $0.005^{*}$ \\
\hline
\end{tabular}

Adjustment for socio-demographic and economic characteristics (age, sex, geographical location, ethnic group, educational background, marital status and total income); $\mathrm{R}^{2}=0.109$; Adjusted $\mathrm{R}^{2}=0.082$; $\mathrm{SE}$ denotes Standard Error; Linear Regression Model significance $<0.0001$; *Significant at $\mathrm{p}<0.05$; ${ }^{a}$ BMI - Body Mass Index (weight in $\mathrm{kg} / \mathrm{height} \mathrm{in} \mathrm{m}^{2}$ ) 


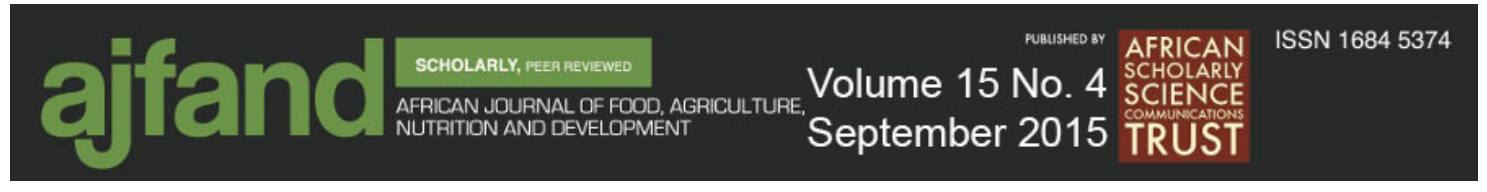

\section{REFERENCES}

1. World Health Organization Nutrition for Health and Development: A Global Agenda for Combating Malnutrition. Geneva: World Health Organization, 2000.

2. British Medical Association Health profiles of older people. In: Health and ageing web resource. British Medical Association, London. Available at: http://www.bma.org.uk/ap.nsf/Content/HAhlthprofile. ( Accessed April 7, 2010).

3. Cummings SR, Black DM, Nevitt MC, Browner W, Cauley J, Ensrud K, Genant HK, Palermo L, Scott $\mathbf{J}$ and TM Vogt Bone Density at Various Sites for Prediction of Hip Fractures: the Study of Osteoporotic Fractures Research Group. The Lancet, 1993; 341: 72-75.

4. Morley JE Anorexia, Sarcopenia, and Aging. Nutrition, 2001; 17: 660-663.

5. Ghana Statistical Service 2000 Population and Housing Census, Summary Report of Final Results. Accra, Ghana: Ghana Statistical Service, 2002.

6. Lesourd BM Nutrition and immunity and the elderly: Modification of immune responses with nutritional treatments. American Journal of Clinical Nutrition, 1997; 66(suppl.): 478s-484s.

7. Wardlaw GM Contemporary Nutrition, Issues and Insights. $5^{\text {th }}$ ed. New York: McGraw-Hill, 2003: 41, 305-307, 513-536.

8. Apt NA Rural ageing in Ghana: Evidence from the field. Position paper presented to the Expert Group Meeting on Rural Aging, Shepherdstown, WV, May, 1999.

9. Moore DS and GP McCabe Introduction to the Practice of Statistics. $2^{\text {nd }}$ ed. New York: W. H. Freeman and Co., 1993: 583.

10. Ismail $\mathbf{J}$ and $\mathbf{M}$ Manandhar Better Nutrition for Elderly People: Assessment and Action. HelpAge International and the London School of Hygiene and Tropical Medicine, London. 1999: 15-36.

11. Schlenker ED Nutrition for Aging and the Aged. In: Williams RS and BS Worthington-Roberts (Eds.) Nutrition Throughout the Life Cycle. $2^{\text {nd }}$ ed. St. Louis: Mosby, 1992: 344-380.

12. Heuberger $\mathbf{R}$ Special Topics in Nutrition and the Diet of the Older Adult: Diet, Lifestyle, Disease, and Pharmacologic Considerations. In: Edelstein S and $\mathrm{J}$ Sharlin (Eds.) Life Cycle Nutrition: An Evidence-Based Approach. Massachusetts: Jones and Bartlett Publishers, 2009: 377-406.

13. Waite LJ The Demographic faces of the elderly. Population Development Reviews, 2004; 30: 3-16. 


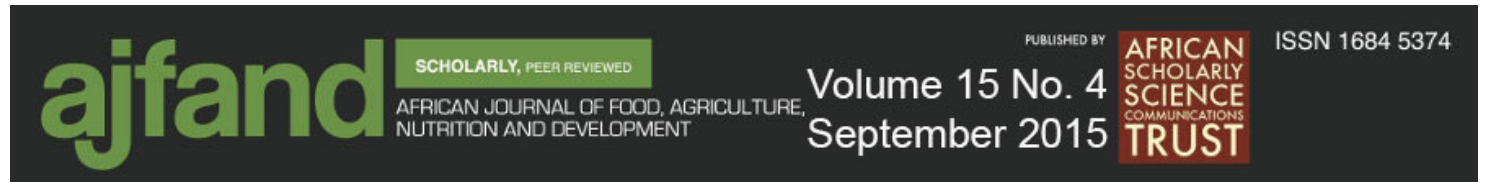

14. Hokby A, Reimers A and I Laflamme Hip fractures among older people: Do marital status and type of residence matter? Journal of Public Health, 2003; 117: 196-201.

15. Wylie C, Copeman J and SFL Kirk Health and social factors affecting the food choice and nutritional intake of elderly people with restricted mobility. Journal of Human Nutrition and Diet, 1999; 12: 375-380.

16. Larrieu S, Letenneur L, Berr C, Dartigues JF, Ritchies $\mathrm{K}$ and A Alperovitch Sociodemographic differences in dietary habits in a population based sample of elderly subjects: The 3C study. Journal of Nutrition, Health and Aging, 2004; 8: 497-502.

17. deGroot PCPGM, van Staveren WA and JGAJ Hautvast Euronut SENECA. Nutrition and the elderly in Europe. European Journal of Clinical Nutrition, 1991; 45(suppl. 3): 1-196.

18. Norgan NG Body mass index and body energy stores in developing countries. European Journal of Clinical Nutrition, 1990; 44: 79-84.

19. Tayie FAK, Adjetey-Sorsey E, Armah J, Busolo D and E Imaya Prevalence of Undernutrition among Elderly Persons in Accra. Ghana Medical Journal, 2004; 38(2): 51-55.

20. Chilima DM and SJ Ismail Nutrition and handgrip strength of older adults in rural Malawi. Public Health Nutrition, 2001; 4: 11-17.

21. Manandhar MC, Ankelsaria PS, Myatt M and S Ismail Undernutrition and Functional Ability amongst Poor Elderly People in Urban India. Journal of Nutrition, Health and Aging, 1997; 1: 75-76.

22. Ochola S, Omalla $\mathbf{J}$ and $\mathbf{M}$ Waggah Assessing the nutritional vulnerability, income and risk factors for older people in Nairobi and Machakos District, Kenya. Workshop report on sharing research findings on nutrition for older people. Nairobi: HelpAge International, 2001.

23. HelpAge International Workshop Report on Sharing Research Findings on Nutrition for Older People. Ireland Aid Final Report - Relief Report for Drought Affected Older People in Borena and Warder Zones, Ethiopia. Nairobi, Kenya: African Regional Development Centre, 2001: 10-11.

24. Stevens J, Keil JE, Rust PF, Verdugo RR, Davis CE, Tyroler HA and PC Graves Body mass index and body girth as predictors of mortality in black and white men. American Journal of Epidemiology, 1992; 135: 1137-1146.

25. Solomons NW Health and Ageing. In: Flores, R. and Gillespie, S. Emerging and re-emerging issues in developing countries. International Food Policy Research Institute, 2001. 


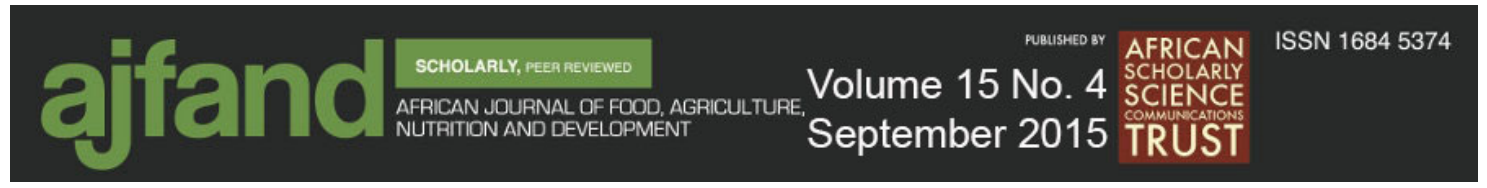

26. Molarius A, Seidall JC, Kuulasmaa K, Dobson AJ and S Sans Smoking and relative weight: an international perspective. World Health Organization MONICA project. Journal of Epidemiology and Community Health, 1997; 51: 252-260.

27. Bovet P, Ross AG, Gervasoni JP, Mkamba M, Mtasiwa DM, Lengeler C, Whiting $\mathbf{D}$ and F Paccaud Distribution of blood pressure, body mass index and smoking habits in the urban population of Dar-es-Salaam, Tanzania and associations with socioeconomic status. International Journal of Epidemiology, 2002; 31: 240-247.

28. Brown JE, Isaacs JS, Krinke UB, Murtaugh MA, Sharbaugh C and J Stang Nutrition Through the Life Cycle. $3^{\text {rd }}$ ed. Belmont, CA: Thomson Wadsworth Company, 2008: 459-470.

29. Boyle MA Community Nutrition in Action: An Entrepreneurial Approach. $3^{\text {rd }}$ ed. New York: Thomson Wadsworth Company, 2003: 336-371.

30. Drinka PJ and JS Goodwin Prevalence and consequence of vitamin deficiency in the nursing home: a critical review. Journal of the American Geriatric Society, 1991; 39: 1008-1017.

31. Payette H, Gray-Donald K, Cyr R and V Boutier Predictors of Dietary Intake in a Functionally Dependent Elderly Population in the Community. American Journal of Public Health, 1995; 85: 677- 683.

32. Joyce GF, Keeler EM, Shang B and GP Goldman The lifetime burden of chronic disease among the elderly. Health Affair, 2005; 24(Suppl. 2): W5R 1829.

33. Hickson M Malnutrition and ageing. Postgraduate Medical Journal, 2006; 82: 2-8.

34. Nygaard H, Tomten SE and AT Hstmart Slow postmeal walking reduces postprandial glycemia in middle-aged women. Applied Physiology, Nutrition and Medicine, 2009; 34(6): 1087-1092.

35. Lieber CS The Influence of Alcohol on Nutritional Status. Nutrition Reviews, 1988; 46: 241-254.

36. Lieber CS Alcohol and nutrition: An overview. Alcohol Health and Research World, 1989; 13: 197-205.

37. International Society for the Enhancement of Eyesight Directory of documents - eye charts, 2009. Available at: www.isee.org. (Accessed June 20, 2010). 


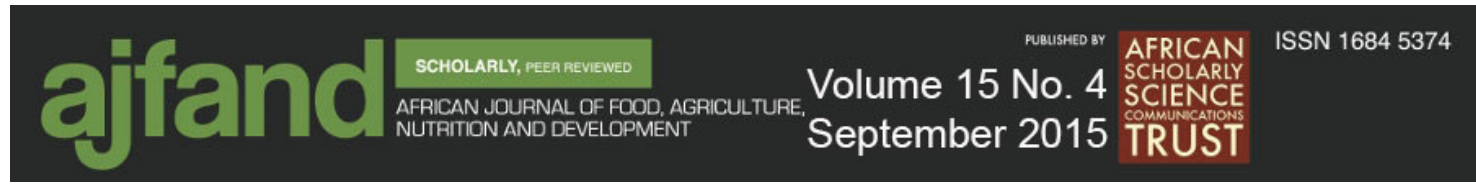

38. Pieterse S, Manandhar $\mathbf{M}$ and $\mathbf{S}$ Ismail The Nutritional Status of Older Rwandan Refugees. Public Health Nutrition, 1998; 1: 259-264.

39. Hofstetter A, Schultz Y, Jequier E and J Wahren Increased 24-Hour Energy Expenditure in Cigarette Smokers. The New England Journal of Medicine, 1986; 314: 79-82.

40. Jacobs DR Jr. and S Gottenborg Smoking and weight: the Minnesota Lipid Research Clinic. American Journal of Public Health, 1981; 71: 391-396. 